\title{
Bandwidth Enhancement of a Micro-strip Patch Antenna with Corner Truncated and U Shape Antenna for Wireless Communications
}

\author{
Puran Gour \\ NIIST Bhopal
}

\author{
RaviShakar Mishra \\ Lovely Professional University \\ Jalandhar Punjab
}

\author{
Pankaj Kumar Singh \\ NIIST Bhopal
}

\begin{abstract}
By using the concept of cutting slots and a hole, a micro-strip patch antenna is designed. In this antenna design we cut a " $U$ " shape on a ground plane and via hole of radius $0.25 \mathrm{~mm}$ placed in between excited patch and ground plane. The antenna is designed on standard FR4 substrate with operating frequency $6 \mathrm{GHz}$. The simulation of proposed antenna is done on IE3D tool and measure characteristics of proposed antenna. We use the material with dielectric constant 4.4, height of material $\mathrm{h}=1.5 \mathrm{~mm}$, loss tangent 0.019 and the operating frequency of material for $6 \mathrm{GHz}$ is introduced.
\end{abstract}

\section{Keywords}

Micro-strip patch antenna (MPA), "U"-shaped slot, Omnidirectional radiation pattern, wireless applications, Bandwidth enhancement, IE3D

\section{INTRODUCTION}

Micro-strip patch antenna is widely used for a wireless communication. It is very popular antenna in communication system, due to their low profile, low cost, easily implement and easily available [4], [6] and [10]. As we already know that micro-strip patch antenna is advantageous over conventional microwave antennas such as light weight, thin profile, dual frequency, and dual polarization, easy fabrication etc. Microstrip patch antenna widely used in various field such as global positioning system (GPS) application, mobile and satellite communication application, radar and telemedicine and radio frequency identification(RFID), WiMAX [1]-[3], [9]. The wireless communication system become more and more popular in these days, which results to develop and interest to work on improvement of antennas performance, However antenna has its inherently shortcomings as narrow impedance bandwidth, low gain and efficiency, much intensive research has been done in recent years to develop bandwidth enhancement as well as to improve others parameters such as bandwidth, gain, efficiency and small size [5] and [7]-[8]. For efficient results accurate feeding is required and for that resistance as the function of feed location and frequency is estimated accurately.

In this paper micro-strip patch antenna is proposed with a meandered ground plane and truncated all four corners with four $U$ shape cutting slots, and a hole of radius $0.25 \mathrm{~mm}$. The micro-strip feed line which comes under the mender slot is considered as a tuning stub for the designed structure.

\section{DESIGN AND CONFIGURATION OF MICROSTRIP PATCH ANTENNA.}

A mender slot is design in the ground plane with four truncated corner and a four $\mathrm{U}$ shape slot cutting with via a hole of radius $0.25 \mathrm{~mm}$. The dimension of micro-strip ground plane is length (L), width (W), it is as $(\mathrm{W} \times L)$, is placed on the other side of the substrate which is use for feeding structure. The work is based on effective value of FR4 substrate with dielectric constant 4.4 and loss tangent 0.019 and operating frequency $6 \mathrm{GHz}$.

Figure 1 and figure 2 shows the back view and front view of the designed structure respectively.

\subsection{The Design of the Ground Plane}

The length $\left(L_{g}\right)$ and width $\left(W_{g}\right)$ of ground plane is expressed as given below-

$$
\begin{aligned}
& L_{g}=\mathrm{L}+6 \mathrm{~h} \\
& W_{g}=\mathrm{W}+6 \mathrm{~h}
\end{aligned}
$$

Where, "h" represents the height of the dielectric constant of substrate. $\mathrm{L}$ and $\mathrm{W}$ represent the length and width (in $\mathrm{mm}$ ) of micro-strip patch respectively.

Where $\mathrm{W}$ and $\mathrm{L}$ are calculated as given below formula-

$$
\begin{gathered}
W=\frac{V o}{2 f r} \sqrt{\frac{2}{\varepsilon r+1}} \\
\mathrm{~L}=\lambda / 2-2 \Delta \mathrm{L}
\end{gathered}
$$

Figure of back view and front view of proposed antenna are shown below.

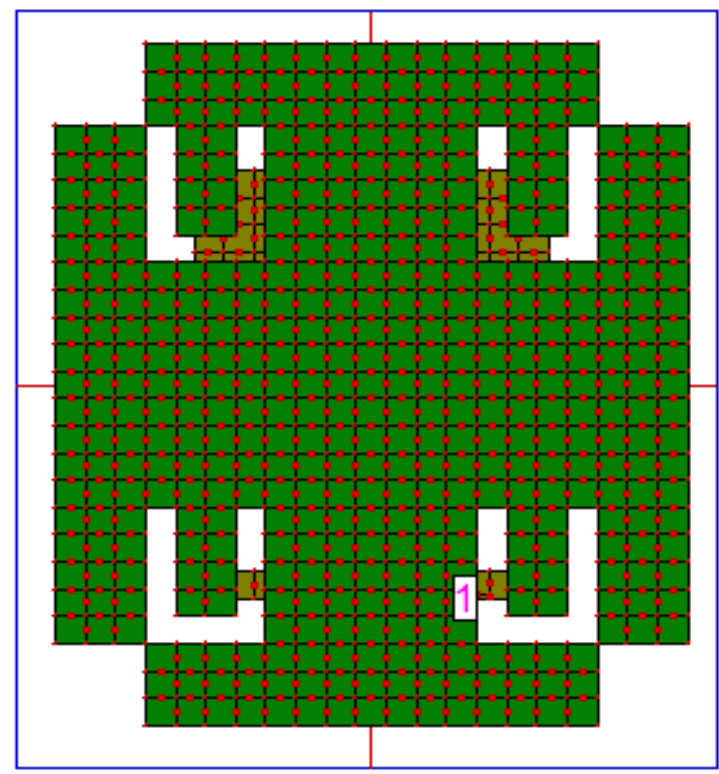

Figure 1 Back View of Proposed Antenna 
From figure here we have four $\mathrm{U}$ shapes structure in a ground plane and such $U$ shape show that the impedance bandwidth improvement. The four corners are truncated to improve the return loss of the proposed antenna.

In next figure 2 of the proposed antenna shows the "U" shape micro-strip exciting patch. The figure 2 shows our top or front view of proposed antenna.

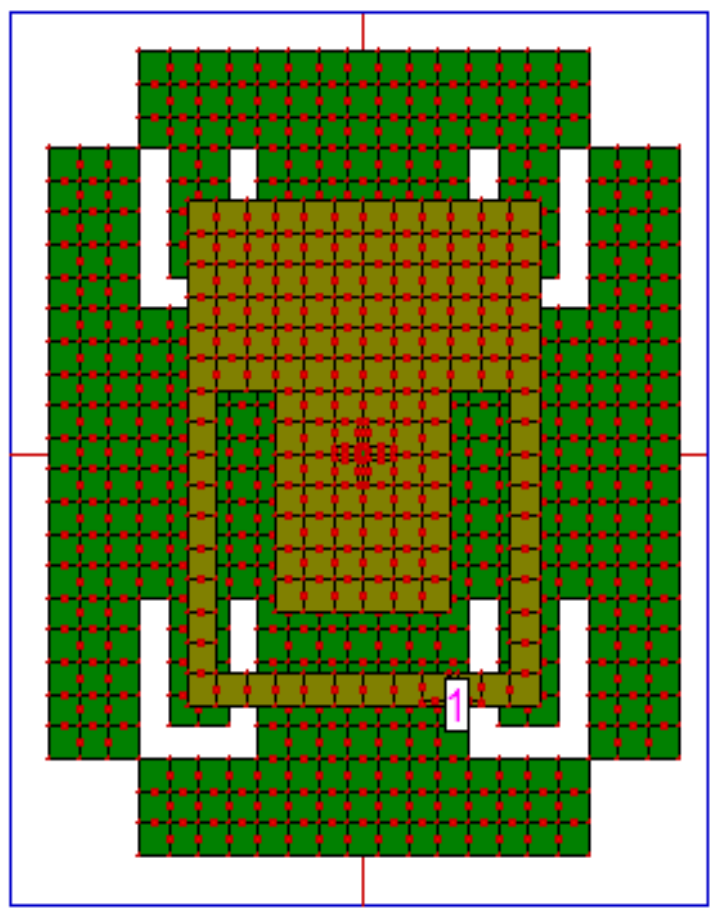

Figure 2 Front view of proposed antenna

Here, the top view of figure 2 shows the top view of proposed antenna. The via a hole which is connected in between ground plane and exciting patch are use to improve the fringing field at the edge of the proposed antenna.

$\Delta L=0.412 h \frac{\left(\varepsilon_{\text {reff }}+0.3\right)\left(\frac{w}{h}+0.264\right)}{\left(\varepsilon_{\text {reff }}-0.258\right)\left(\frac{w}{h}+0.8\right)}$

$\varepsilon_{r}=\frac{\varepsilon_{r+1}}{2}+\frac{\varepsilon_{r-1}}{2} \sqrt{\frac{1}{1+12 \frac{h}{w}}}$

Where, $V_{O}$ represents the speed of light in free space and $\varepsilon_{\text {reff }}$ represents the effective dielectric constant of the substrate. The ground plane dimensions The length $\left(L_{g}=20.3828 \mathrm{~mm}\right)$ and width $\left(W_{g}=24.2 \mathrm{~mm}\right)$ are calculated.

The truncated corners dimensions of proposed antenna are $3 \mathrm{~mm} \times 3 \mathrm{~mm}$. The three dimensional (3D) view of proposed antenna structures is shown in the given below figure 3

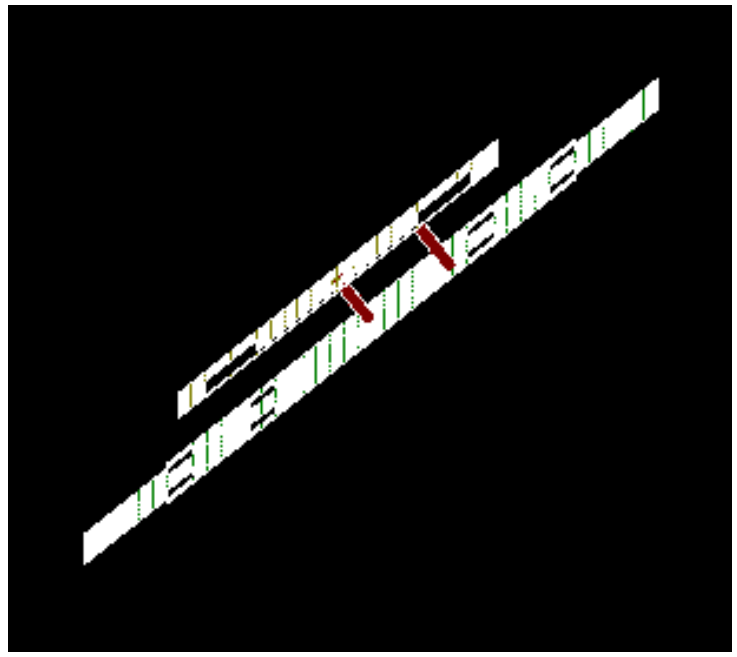

Figure 3: 3D view of proposed antenna

\subsection{Designing of the U Slot.}

The meander slots of four ' $U$ ' shapes are designed with four truncated corner in the ground plane. That have length $(\mathrm{L}=5 \mathrm{~mm})$ and width $(\mathrm{W}=1.5 \mathrm{~mm})$ and $(\mathrm{S}=2 \mathrm{~mm})$ slots in ground plane. On the other side of substrate on excited patch plane a ' $U$ ' shape slot cut a dimension of length $(\mathrm{L}=9 \mathrm{~mm})$ and width $(\mathrm{W}=1.5 \mathrm{~mm})$ and $(\mathrm{S}=10 \mathrm{MM})$. The internal gap of the mender slot is chosen as $1.5 \mathrm{~mm}$.

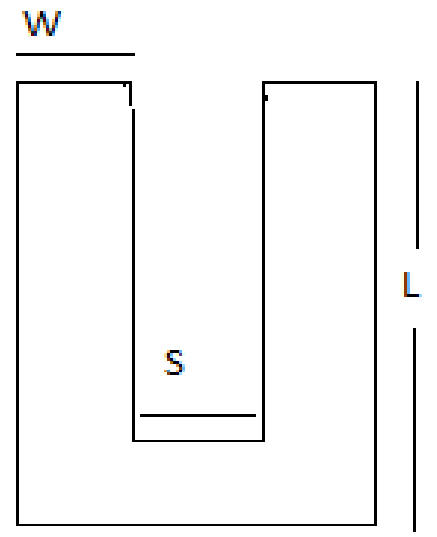

Figure 4: A Ground plane Slot U

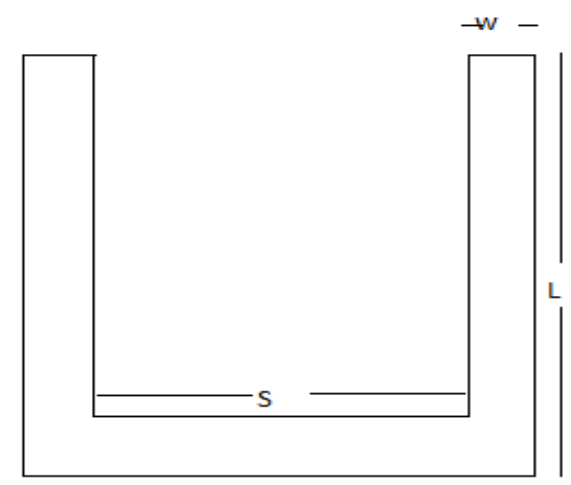

Figure (b) Excited Patch Plane Slot Shape (Top view)

In this configuration of patch antenna via a hole of radius $0.25 \mathrm{~mm}$ are used in the centre and the internal gap of the 
mender slot is chosen as $1.5 \mathrm{~mm}$. Variation in the internal height of the slot tends to variation in the return loss level and impedance bandwidth.

\section{DESIGN CONSIDERATION AND DISCUSSION OF RESULT.}

The dimensions of ground plane structure are $20.3828 \mathrm{~mm} \times$ $24.2 \mathrm{~mm} \times 1.5 \mathrm{~mm}$ are used to proposed the antenna structure. The return loss variations with respect to the frequency are represented in fig. 5 which shows an enhanced impedance bandwidth of $36.94 \%$ in the range from $4.6 \mathrm{GHz}$ to $4.8 \mathrm{GHz}$ and $6.4 \mathrm{GHz}$ to $8.9 \mathrm{GHz}$.

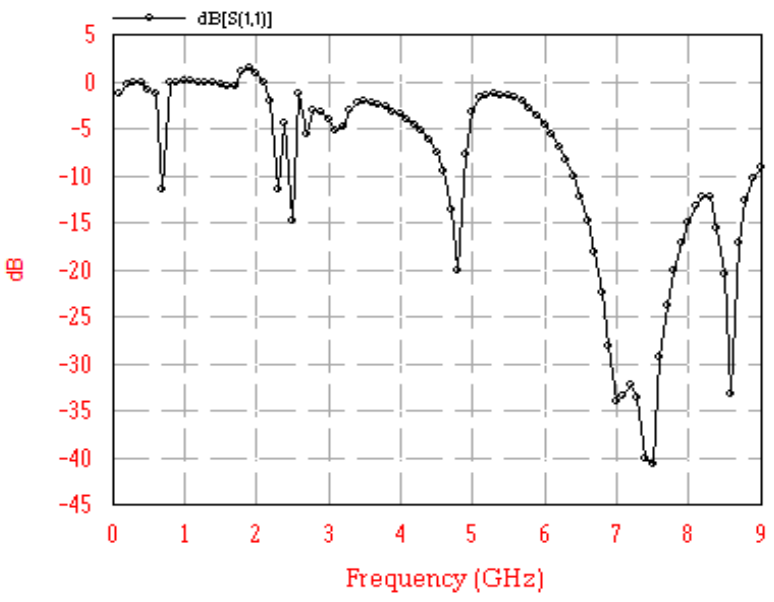

Figure 5 simulated values of S11 vs. Frequency

The directivity defines the maximum directional gain of an antenna in a particular direction and is found up to $6 \mathrm{dBi}$. in the operating range shown as in figure 6 .

\section{Directivity Vs. Frequency}

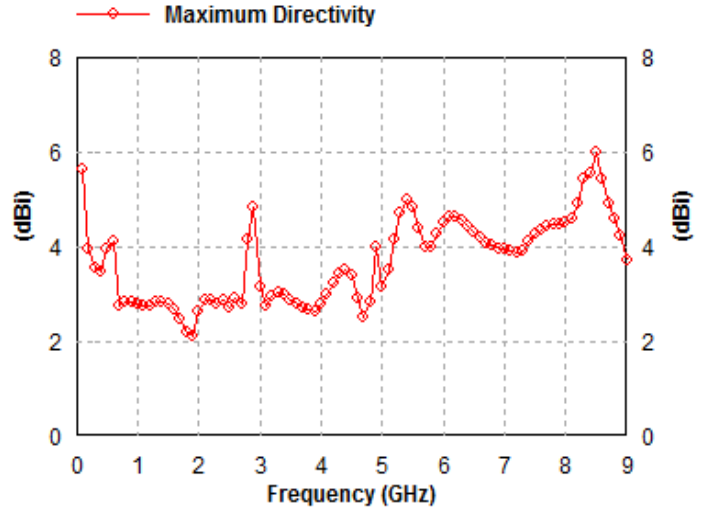

Fig.6: Simulated values of directivity vs frequency.

The maximum gain of proposed antenna is $5.5 \mathrm{dBi}$. It is shown in figure7.
Gain Vs. Frequency

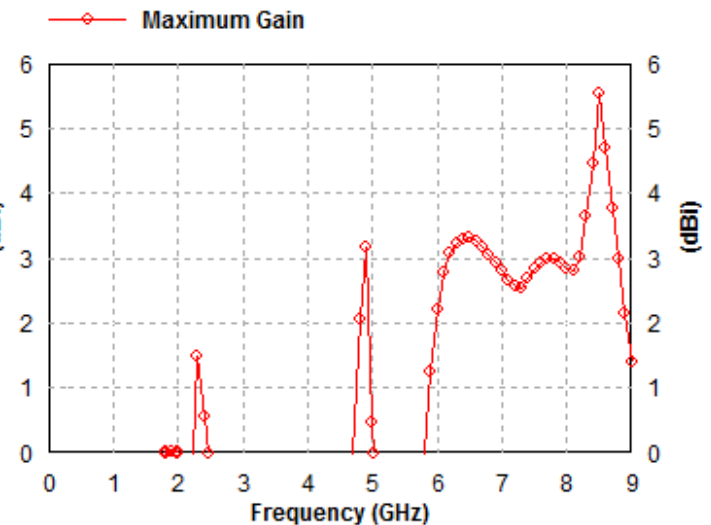

Figure.7 Simulated values of gain vs. frequency

The radiation patterns for the designed structures at frequency 7.5 GHz. Radiation pattern defines the mathematical function or a graphical representation of the radiation properties of the antenna as a function of space coordinates. The radiation pattern of proposed antenna is shown in given below in figure 8

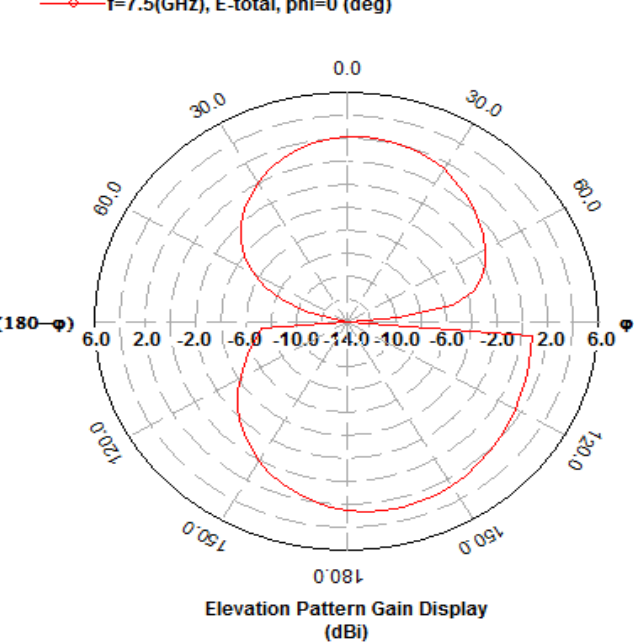

Figure 8: Radiation pattern of the proposed structure at $7.5 \mathrm{GHz}$.

The maximum antenna efficiency and radiating efficiency for proposed structure is found to be $91 \%$ and $100 \%$ respectively and it is shown in given figure 9 . 


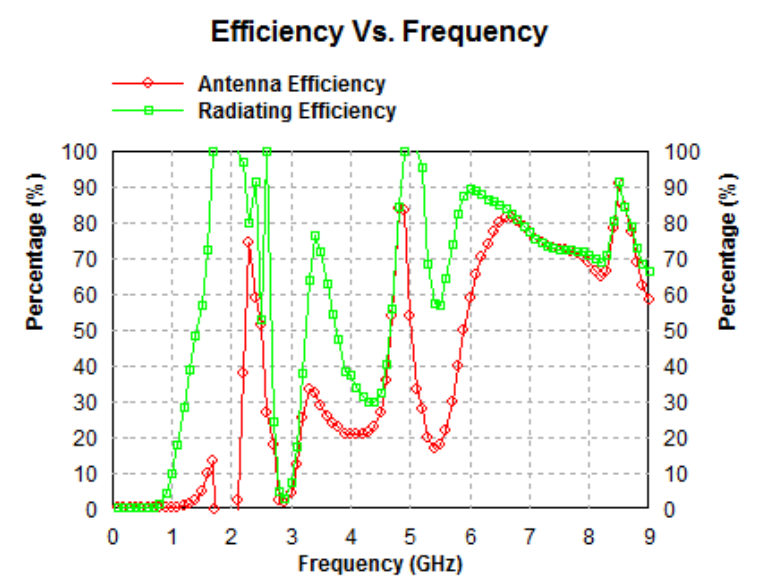

Figure 9 Simulated values of efficiency vs. Frequency.

AXIAL-RATIO OF PROPOSED ANTENNAThe axial ratio of proposed antenna defines the ratio of the major to minor axes of the polarization ellipse. Axial ratio of the proposed antenna is shown in the given figure 10.

\section{Axial-Ratio Vs. Frequency}

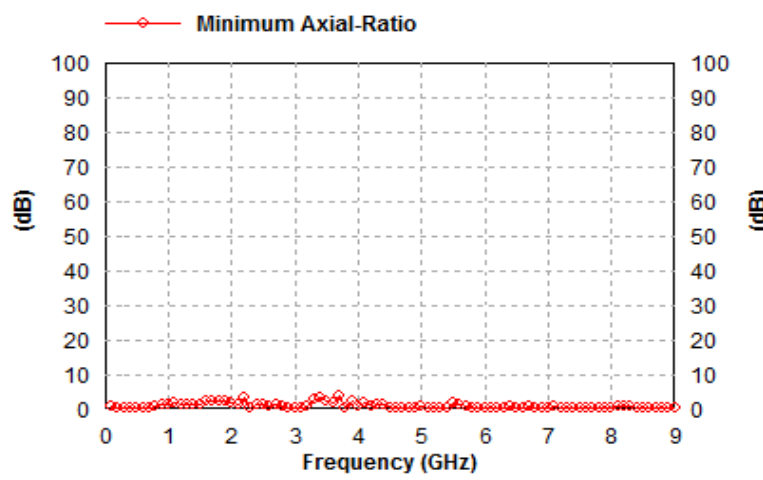

Figure 10 Axial-ratio of proposed antenna

\section{CONCLUSION}

A compact micro-strip patch antenna for enhancing gain and bandwidth has been designed and simulated successfully. This proposed antenna has a very simple structure. The micro-strip patch antenna with meandered ground plane and four truncated corners is designed. An impedance bandwidth of proposed antenna is $36.94 \%$ in the range of $4.8 \mathrm{GHz}$ to 8.9 $\mathrm{GHz}$ frequency. The gain of $5.5 \mathrm{dBi}$ is achieved in impedance bandwidth. Thus proposed structure is suitable for wireless communication. The antenna characteristic and radiation pattern are satisfactory for most of the indoor wireless system.

\section{REFERENCES}

[1] Hang Wong, Kwok Kan So and Xia Gao "Bandwidth enhancement of a mono-polar patch antenna with $\mathrm{V}$ - shaped slot for car to car and WLAN communication" IEEE, Transactions on vehicular Technology-2015.

[2] Mrs.Devashree S.Marotkar and Dr. Prasanna Zade "Bandwidth enhancement of micro-strip patch antenna using defected ground structure" IEEE, International conference on Electrical, Electronics and optimization techniques-2016

[3] Ajay Thatere, Dr.P.L.Zade and Dwejendra Arya "Bandwidth enhancement of micro-strip patch antenna using "U" slot with modified ground plane" IEEE, International conference on Microwave, optical and communication Engineering, IIT Bhubaneswar India December 18-20,2015

[4] Achmad Munir, Guntur Petrus and Hardi Nusantara "Multiple slot technique for bandwidth enhancement of micro-strip rectangular patch antenna" IEEE, Research grant from ITB under the scheme program of research and Innovation-2013

[5] Bashir D.Bala, Mohamad Kamal A.Rahim and N.A.Murad "Bandwidth enhanced micro-strip patch antenna using meta-materials" IEEE, Asia-Pacific conference on Applied Electromagnetic, December 1113,2012

[6] Ram Singh Kushwaha, D.K.Srivastava, J.P.Saini and Seema Dhupkariya "Bandwidth enhancement for microstrip patch antenna with micro-strip line feed" IEEE, Third International conference on computer and communication technology-2012

[7] Pratibha B. Pramar, Balvant J. Makwana and Mehul A. Jajal "Bandwidth enhancement of micro-strip patch antenna using parasitic patch configuration" IEEE, International conference on communication systems and network technology-2012

[8] H.F.Abu Tarboush, H.S.Al-Raweshidy and R.Nilavalan "Bandwidth enhancement for micro-strip patch antenna using stacked patch and slot" IEEE, Wireless network and communication centre, school of engineering and design Brunel University West London U.K.-2009

[9] M.D.Van Wyk and K.D.Palmer "Bandwidth enhancement of micro-strip patch antenna using coupled lines" IEEE, Electronics letters Vol. 37 no.13, 21st June 2001.

[10] Ravi Kant Prasad, D.K.Srivastava and J.P. Saini "Gain and bandwidth enhancement of rectangular micro-strip antenna by loading slot" IEEE, 1st International conference on innovation and challenges in Cyber Security-2016. 